\title{
Efeito da adição do gesso agrícola em substrato no desenvolvimento de mudas de cafeeiro
}

Lierge Ramos- Tecnólogo em Cafeicultura email: lierg.ramos@yahoo.com.br; Dulcimara Carvalho Nannetti- Prof.a $\mathrm{Dr}^{\mathrm{a}}$. do Instituto Federal de Educação, Ciência e Tecnologia - Campus Machado-MG rodovia Machado-Paraguaçu, km 07, CEP 37.750-000. email: dulcimara@eafmachado.gov.br; Davi Lopes do Carmo- Mestrando em Ciência do

Solo pela Universidade Federal de Lavras-MG (DCS/UFLA). email: davigoldan@yahoo.com.br

\section{RESUMO}

O experimento foi conduzido em uma propriedade agrícola no município de Machado, Sul de Minas Gerais, com objetivo de avaliar a resposta das mudas de cafeeiro de cultivar Topázio MG 11-19 mediante a aplicação de doses crescentes de gesso agrícola ao substrato. O delineamento experimental foi o de blocos casualizados em um esquema fatorial com 6 tratamentos e 4 repetições. No final do experimento, as plantas foram colhidas, separadas em folha, caule e raiz, lavadas e secas para a obtenção do diâmetro do caule, área foliar, massa seca da parte aérea, massa seca de raiz, altura da planta e comprimento da raiz. As mudas foram formadas em saquinhos de polietileno, com a utilização do substrato padrão estabelecido pela cultura com um acréscimo de 6 doses diferentes de gesso agrícola, constituindo-se em seis diferentes tratamentos ( $0 \mathrm{~kg}, 2,5 \mathrm{~kg}, 5 \mathrm{~kg}, 10 \mathrm{~kg}, 20 \mathrm{~kg}$ e $40 \mathrm{~kg}$ ) de gesso, para $1 \mathrm{~m}^{-3}$ de substrato. Com relação aos parâmetros diâmetro do caule e altura das plantas, a análise estatística mostrou que houve maiores incrementos nos valores para os tratamentos em torno de 10 a $15 \mathrm{~kg}$ de gesso agrícola por $\mathrm{m}^{-3}$ de substrato. Isso mostra que existe uma necessidade de complementação nutricional para um bom desenvolvimento das mudas de cafeeiro. Tanto doses menores, quanto doses maiores mostram efeitos negativos nos parâmetros de crescimento. Na dose zero de gesso agrícola, todas as características de crescimento das mudas estudadas apresentaram os menores valores. Com relação à massa seca de raiz, massa seca de parte aérea, comprimento da raiz e área foliar não apresentou diferença significativa em função dos tratamentos, mas, houve um incremento nos valores médios dos parâmetros avaliados até a dose de $15 \mathrm{~kg}$ de gesso agrícola por $\mathrm{m}^{-3}$ de substrato.

Palavras - chave: gesso agrícola, parâmetros de crescimento, formação de mudas.

\section{Effect of addition of agricultural gypsum substrate in the development of coffee seedlings}

\begin{abstract}
The experiment was conducted on a farm in the municipality of Machado, southern Minas Gerais, to evaluate the response of coffee plants to cultivat Topázio MG 11-19 by applying increasing doses of gypsum to the substrate. The experimental design was randomized blocks in a factorial design with 6 treatments and 4 replicates. At the end of the experiment, the plants were harvested, separated into leaves, stem and root, washed and dried to obtain the stem diameter, leaf area, shoot dry mass, root dry weight, plant height and root length. The seedlings were grown in polyethylene bags, with the substrate utilization pattern established by culture with an addition of six different doses of gypsum, being in six different treatments $(0 \mathrm{~kg}, 2.5 \mathrm{~kg}, 5 \mathrm{~kg}, 10$ $\mathrm{kg}, 20 \mathrm{~kg}, 40 \mathrm{~kg}$ ) of plaster for a $\mathrm{m}^{-3}$ substrate. The parameters: stem diameter and plant height, statistical analysis showed that there were greater increases in the values for the treatments in
\end{abstract}


about 10 to $15 \mathrm{~kg}$ of gypsum per m-3 substrate. This shows that there is a need for additional nutrition for the healthy development of coffee seedlings. Much smaller doses, as higher doses showed negative effect on growth parameters. At zero gypsum, all seedling growth characteristics studied showed the lowest values. With respect to root dry weight, shoot dry weight, root length and leaf area showed no significant difference in the treatments, but there was an increase in the average values of these parameters until the dose of 15 $\mathrm{kg}$ of gypsum per $\mathrm{m}^{-3}$ substrate.

Key-words: gypsum, growth parameters, seedling production.

\section{INTRODUÇÃO}

A produção de café é uma das atividades agrícolas mais importantes para a economia brasileira, sendo o Brasil o maior produtor mundial, tendo registrado uma produção de 39.470 milhões de sacas em 2009. Dentro deste contexto, o estado de Minas Gerais é o maior produtor brasileiro, respondendo por cerca de 19.880 milhões de sacas ou $50 \%$ da produção nacional (Conab, 2009).

O substrato proporciona influência significativa no crescimento e desenvolvimento das mudas de cafeeiro devido ao ambiente onde o sistema radicular se desenvolve e a nutrição proporcionada pelo mesmo, com reflexos no crescimento e vigor vegetativo das mudas até o momento de seu plantio. A utilização de mudas de qualidade é um fator fundamental para aumentar a longevidade da lavoura cafeeira, pois interfere decisivamente no desenvolvimento da cultura, e consequentemente na sua produtividade (Campos, 2002). Diversos trabalhos foram realizados na busca de um substrato ideal e de uma nutrição adequada para as mudas de cafeeiro, no entanto, atualmente adota-se como substrato padrão conforme recomenda o $5^{\circ}$ Aproximação (Guimarães et al.1999), com uma recomendação de: $700 \mathrm{~L}$ de terra, $300 \mathrm{~L}$ de esterco bovino (ou 80 litros de esterco de galinha, ou ainda 10 a 15 litros de torta de mamona), 3 a $5 \mathrm{Kg}$ de Superfosfato Simples, 0,5 a $1,0 \mathrm{Kg}$ de cloreto de potássio. A fertilidade do substrato pode ser elevada mediante ao emprego de fertilizantes minerais e orgânicos e corretivos.

A maioria dos trabalhos realizados com substratos comerciais na formação de mudas de cafeeiro enfoca, predominantemente, aspectos químicos do material, como a dose a ser aplicada, sua composição em nutrientes, a solubilidade da fonte e o tempo de liberação dos nutrientes (Favarin et al., 2008). Entretanto, são escassos trabalhos referente ao uso do gesso agrícola na produção de mudas cafeeiras. Alguns produtores de mudas de café acrescentam gesso agrícola ao substrato na proporção de $40 \mathrm{~kg}$ de gesso por metro cúbico de substrato.

O gesso agrícola é um sub-produto da indústria de fertilizantes fosfatados concentrados e contém cerca de $20 \%$ de cálcio, $15 \%$ de enxofre, $0,7 \%$ de $\mathrm{P}_{2} \mathrm{O}_{5}$ e $0,6 \%$ de flúor e os seus principais benefícios estão ligados ao fornecimento do cálcio, enxofre e diminuição da saturação por alumínio (Furtini Neto et al., 2001). Podendo provocar alterações químicas no substrato, principalmente relacionadas à diminuição da saturação por alumínio e ao aumento da saturação por bases, além de fornecer cálcio e enxofre às plantas. A alteração da constituição da solução do solo mediante a aplicação de gesso agrícola é, sobretudo, consequência dos incrementos dos teores de $\mathrm{Ca}$ e de $\mathrm{S}_{-} \mathrm{SO}_{4}{ }^{-2}$, por serem os elementos presentes em maiores proporções nesse produto (Faria et al., 2003).

Considerando os possíveis benefícios que o gesso agrícola pode fornecer às culturas, realizou-se este estudo objetivando avaliar seu efeito sobre o desenvolvimento da formação de mudas de cafeeiro de cultivar Topázio MG 11-19. 


\section{MATERIAL E MÉTODOS}

O experimento foi conduzido no período de outubro de 2009 a março de 2010 em propriedade agrícola, localizada no bairro Passa Dois, Sítio S. João, município de Machado Sul de Minas Gerais. O clima da região é o Cwa, segundo a classificação de Koppen, apresentando temperaturas moderadas, com verão quente e chuvoso. A temperatura média anual é de $21,2^{\circ} \mathrm{C}$, a média mensal máxima de $27{ }^{\circ} \mathrm{C}$, a média mensal mínima de $14,2{ }^{\circ} \mathrm{C}$ e o índice pluviométrico médio anual de 1.824 $\mathrm{mm}$ (Marques, 2003). As mudas foram formadas em saquinhos de polietileno 11 x 22 $\mathrm{cm}$, sendo o substrato utilizado para mudas de cafeeiro, constituído de $700 \mathrm{~L}$ de terra de subsolo peneirada, $300 \mathrm{~L}$ de esterco de curral curtido e peneirado, $10 \mathrm{~kg}$ de Superfosfato Simples e $5,0 \mathrm{~kg}$ de cloreto de potássio. Foi utilizada como cobertura para controle de insolação, tela do tipo sombrite, de cor preta, com passagem de $50 \%$ de luz, posicionada a dois metros acima dos saquinhos, assim como na parte lateral do viveiro, para evitar a incidência direta da luz solar sobre as mudas. Os canteiros foram de material alternativo (bambu), onde foram conduzidos os diferentes tratamentos. Foi realizado a semeadura direta com a cultivar Topázio MG 1119 adquiridas através da EPAMIG (Empresa de Pesquisa Agropecuária de Minas Gerais), a $1 \mathrm{~cm}$ de profundidade.

O desbaste da planta menos vigorosa após o surgimento do primeiro par de folhas foram realizados conforme as recomendações de Matiello et al., 2005. As regas foram realizadas duas vezes ao dia (manhã e tarde) da semeadura até a fase "orelha de onça", com a utilização de uma mangueira. A partir desta fase, o suprimento de água foi realizado uma vez ao dia. Plantas daninhas que eventualmente surgiam, foram manualmente eliminadas.

O delineamento foi em blocos casualizados, onde avaliou-se 6 doses de gesso agrícola, em 4 repetições. As parcelas eram constituídas de oito mudas, totalizando 192 plantas. $\mathrm{O}$ fator foi dose de gesso agrícola e os tratamentos foram $(0 \mathrm{~kg}, 2,5 \mathrm{~kg}, 5 \mathrm{~kg}, 10$ $\mathrm{kg}, 20 \mathrm{~kg}$ e $40 \mathrm{~kg}$, para $1 \mathrm{~m}^{-3}$ de substrato), adicionadas ao substrato convencional com a avaliação dos seguintes parâmetros de crescimento: diâmetro do caule (DC), área foliar (AF), massa seca da parte aérea (MSPA), massa seca de raiz (MSR), altura da planta (AP) e comprimento da raiz (CR), aos 180 dias após a semeadura.

O diâmetro foi medido na base do caule e medido em milímetros ( $\mathrm{mm}$ ) com paquímetro, altura da planta foi determinada a partir da base do caule até o final em $(\mathrm{cm})$. As determinações dos pesos de matéria seca foram efetuadas a partir do material seco em estufa, sendo que, ao final do período experimental as plantas foram colhidas, lavadas em água deionizada e subdivididas com corte das raízes, caule e parte aérea e acondicionados em sacos de papel e posto para secar em estufa de circulação de ar a $70^{\circ} \mathrm{C}$ até atingir peso constante, conforme descrito por Jones Junior et al. (1991). As plantas subdivididas foram pesadas em balança de precisão e o resultado expresso em gramas por planta (g planta $\left.{ }^{-1}\right)$.

Os dados obtidos foram submetidos à análise de variância, pelo programa estatístico SISVAR (Ferreira, 2000) com a aplicação de teste de F, considerando-se a significância no nível de $5 \%$ de probabilidade e os gráficos gerados pelo programa Sigma Plot 11.0.

\section{RESULTADOS E DISCUSSÃO}

Observa-se na tabela 1 , pelo teste $\mathrm{F}$, ao nível de 0,05 , que a altura da planta e o diâmentro do caule, apresentaram diferença significativa, enquanto que, a área foliar, crescimento da raiz, massa seca da parte aérea e massa seca de raiz não diferenciaram significativamente, considerando em função das diferentes doses de gesso agrícola adicio- 
nado ao substrato para a produção de mudas.

Os coeficientes de variação apresentam valores de baixo a médio e somente as variáveis massa seca da parte aérea e massa seca da raiz apresentaram um pouco mais elevada em relação aos demais parâmetros.

Tabela 1. Resumos das análises de variância para as variáveis avaliadas (AP: altura da planta; AF: área foliar; CR: crescimento da raiz; DC: diâmetro do caule; MSPA: massa seca da parte aérea; MSR: massa seca de raiz) no experimento sobre doses de gesso adicionadas ao substrato para a produção de mudas de cafeeiro (Coffea arabica L.).

\begin{tabular}{lccccccc} 
& & \multicolumn{5}{c}{ Teste de F } \\
\cline { 3 - 7 } $\begin{array}{l}\text { Causas de } \\
\text { Variação }\end{array}$ & G.L & AP & AF & CR & DC & MSPA & MSR \\
Bloco & & $(\mathrm{cm})$ & $\left(\mathrm{cm}^{2}\right)$ & $(\mathrm{cm})$ & $(\mathrm{mm})$ & \multicolumn{2}{c}{$(\mathrm{g})$} \\
\cline { 3 - 8 } Doses & 3 & $0,00^{* *}$ & $0,51^{\text {ns }}$ & $0,10^{\text {ns }}$ & $0,00^{* *}$ & $0,70^{\text {ns }}$ & $0,29^{\text {ns }}$ \\
\hline CV $(\%)$ & 5 & $0,04^{*}$ & $0,38^{\text {ns }}$ & $0,06^{\text {ns }}$ & $0,03^{*}$ & $0,38^{\text {ns }}$ & $0,46^{\text {ns }}$ \\
\hline
\end{tabular}

**, * e ns : Significativos a 1 e $5 \%$ e não significativos pelo teste $\mathrm{F}$, respectivamente.

O diâmetro do caule é considerado por muitos pesquisadores como sendo um importante parâmetro para estimar a sobrevivência logo após o plantio, de mudas de diferentes espécies (Gomes, 2001). No presente trabalho, com relação ao parâmetro diâmetro do caule, a análise estatística mostrou que houve maiores incrementos nos valores para os tratamentos em torno de 10 a $15 \mathrm{~kg}$ de gesso agrícola por $\mathrm{m}^{-3}$ de substrato.

Analisando o comportamento das equações de regressão da figura 1, observa-se que foram alcançados pontos de máximo crescimento (altura da planta e diâmetro do caule) correspondente à dose de $15 \mathrm{~kg} \mathrm{~m}^{-3}$. Isso mostra que existe uma necessidade de complementação nutricional para um bom desenvolvimento das mudas de cafeeiro. Tanto doses menores, quanto doses maiores mostram efeitos negativos nos parâmetros de crescimento. Observa-se ainda que na dose zero de gesso agrícola, todas as características de crescimento das mudas estudadas apresentaram os menores valores.

A altura da parte aérea fornece uma excelente estimativa da predição do crescimento inicial no campo, sendo tecnicamente aceita como uma boa medida do potencial de desempenho das mudas, apesar de que esse parâmetro pode ser influenciado por várias práticas que são adotadas nos viveiros (Mexal e Lands, 1990). Para esse parâmetro, a análise estatística mostrou ter havido resposta significativa das mudas de cafeeiro aos tratamentos com dosagem de 10 a $15 \mathrm{~kg}$ de gesso agrícola por $\mathrm{m}^{-3}$ de substrato. A altura é considerada como um dos parâmetros importante na classificação e seleção de mudas (Parviainen, 1981), tendo em vista que as maiores alturas corresponderam, no campo, à maior taxa de sobrevivência e ao maior crescimento inicial.

Com relação à massa seca de raiz, massa seca de parte aérea, comprimento da raiz e área foliar não apresentou diferença significativa em função dos tratamentos, mas, houve um incremento nos valores médios dos parâmetros avaliados até a dose de $15 \mathrm{~kg}$ de gesso agrícola por $\mathrm{m}^{-3}$ de substrato. Os melhores desempenhos observados nos parâmetros de crescimento das mudas de cafeeiro mediante a adição de gesso ao substrato se devem possivelmente aos teores de cálcio e enxofre presente no gesso agrícola, sendo o cálcio importante no crescimento radicular, além do seu papel na divisão e alongamento das células.

Hsiao (1973) indicou que o crescimento das plantas é controlado pela divisão celular, seguido de sua expansão e Malavolta (2006) relata que conforme as células crescem, 
após a multiplicação, precisam constantemente de cálcio para a formação da parede. Ragassi (2007) relata que o cálcio ligado como pectato, na parede celular, é essencial para seu
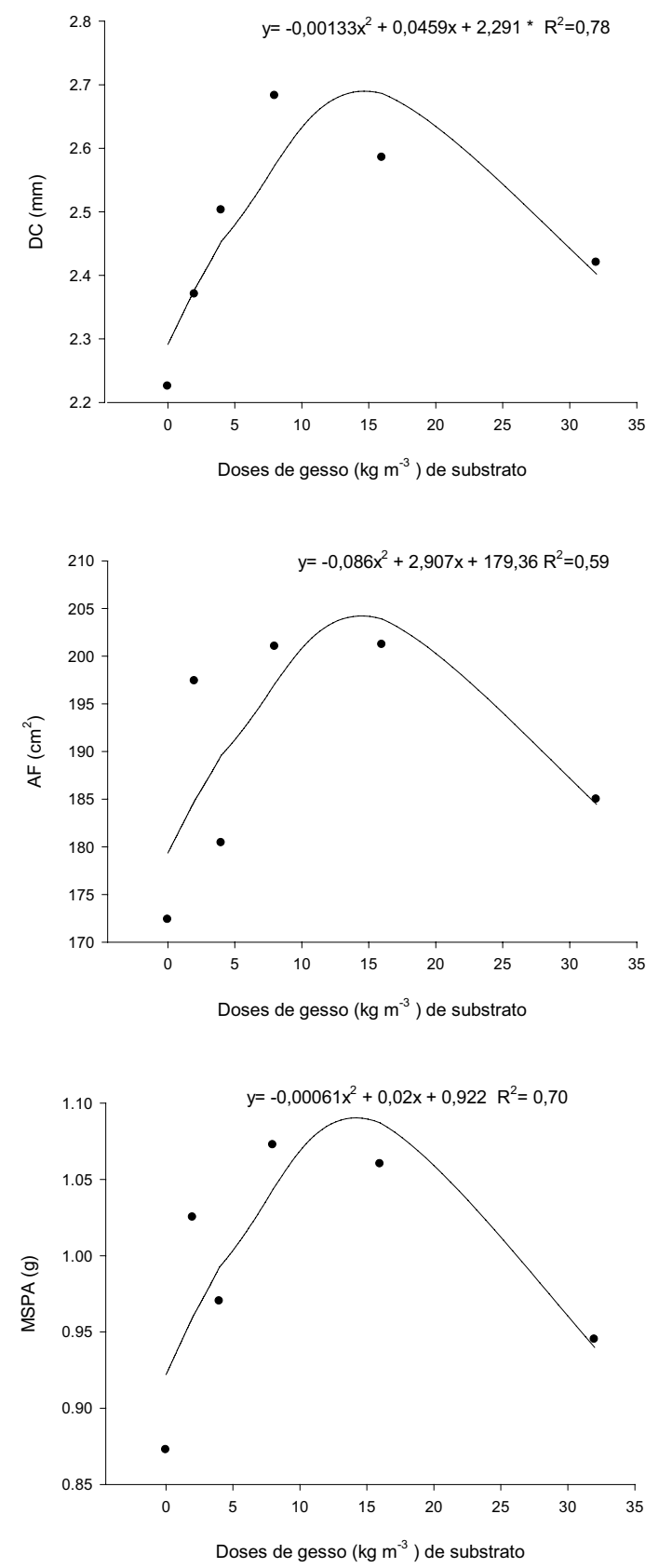

fortalecimento e dos tecidos formados, a proporção de pectato de cálcio na parede celular é muito importante para a resistência do tecido a infecções causadas por fungos e bactérias.
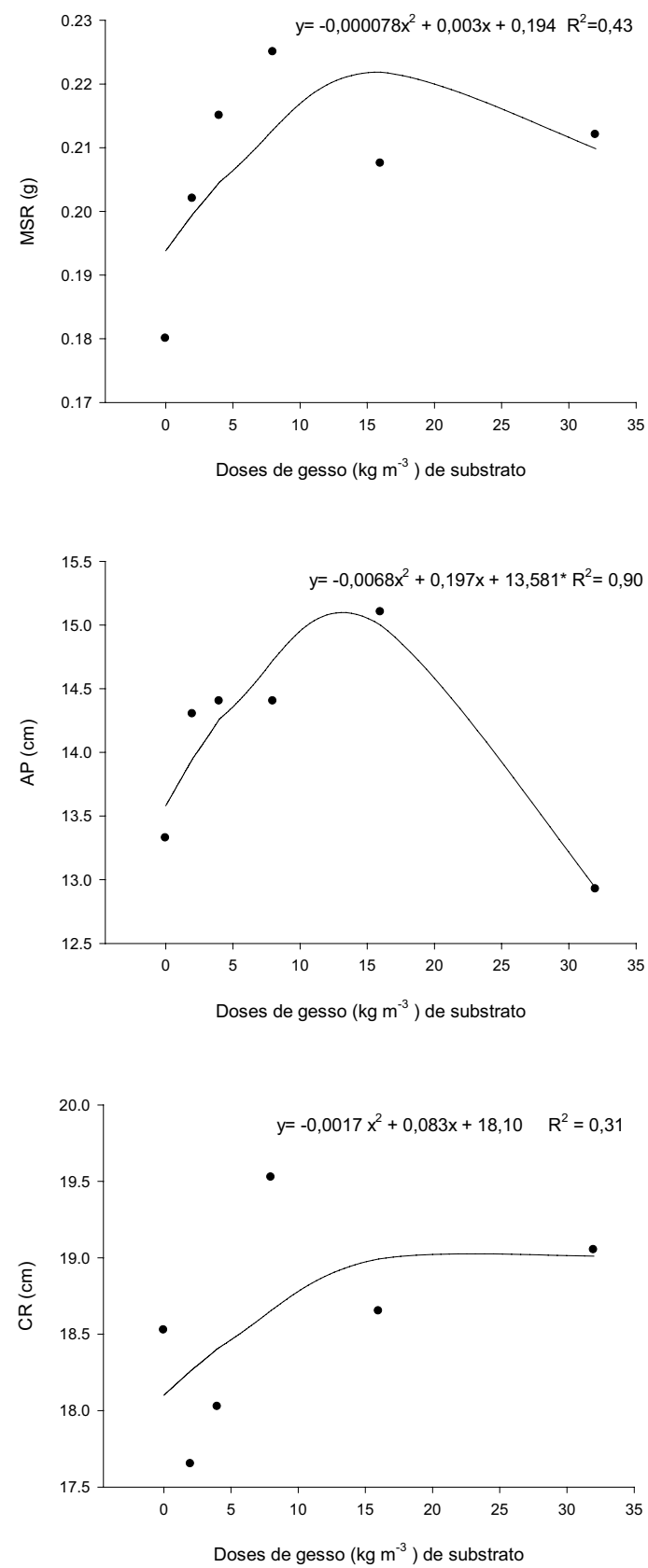

FIGURA 1 - AP: altura da planta; AF: área foliar; CR: crescimento da raiz; DC: diâmetro do caule; MSPA: massa seca da parte aérea; MSR: massa seca de raiz, em função das crescentes doses de gesso agrícola adicionadas ao substrato. Machado, 2010.

Segundo Carneiro (1995), o enxofre e o cálcio são elementos essenciais para uma eficiente utilização de nitrogênio e seu metabolismo. O crescimento celular é resultante

dos processos de divisão celular e alongação, e, segundo Shelp (1993), o cálcio é necessário para que ocorram ambos os processos e sua carência inibe o crescimento radicular. Em 
um estudo realizado por Chaves et al. (1991) em mudas de cafeeiro por um período de dez meses mostrou que houve aumento no peso da matéria seca das plantas com a elevação do $\mathrm{Ca}^{2+}$ e diminuição de $\mathrm{Al}^{3+}$ na solução do solo.

Uma das principais funções do enxofre nas plantas é a de ser constituinte dos aminoácidos cisteína e metionina, essenciais para a biossíntese de proteínas e para a atividade de certas enzimas. Além disto, este macronutriente é componente de inúmeras coenzimas e grupos prostéticos, como tiamina pirofosfato (TPP), ácido lipóico e coenzima A, que são essenciais para o funcionamento do sistema multienzimático, que controla a descarboxilação do piruvato necessário para iniciar o funcionamento do ciclo de Krebs (Taiz e Zeiger, 2002). O enxofre também é constituinte da ferredoxina, sulfolipídios e esfingolipídios, moléculas envolvidas em inúmeros processos em que há transferência de elétrons, manutenção e estrutura das membranas celulares (Marschner, 1995; Buchanan, 2000; Taiz e Zeiger, 2002).

\section{CONCLUSÃO}

A adição de gesso agrícola na dosagem de 10 a $15 \mathrm{~kg}$ de por $\mathrm{m}^{-3}$ de substrato padrão como complemento nutricional influenciou positivamente no desenvolvimento vegetativo das mudas de cafeeiro em fase de viveiro.

\section{REFERÊNCIAS BIBLIOGRÁFICAS}

BUCHANAN, B.B., GRUISSEN, W.; JONES, R.L. Biochemistry and molecular biology of plants. Rockville, Maryland: American Society of Plant Physiologists. 2000. 1367 p.

CAMPOS, K. P. Produção de cafeeiro (Coffea arabica L.) em diferentes espaçamentos, substratos, adubações e tamanho de tubetes. 2002. 90p. Dissertação (Mestrado em Fitotecnia) - Universidade Federal de Lavras. Lavras.
COMPANHIA NACIONAL DE ABASTECIMENTO - CONAB. Disponível em: $<$ http://www.conab.gov.br/conabweb/index. php?PAG $=73 \& N S N=1217>$. Acesso em: 18 de dez. 2009.

CHAVES, J.C. et al. Especiação química da solução do solo para interpretação da absorção de cálcio e alumínio por raízes de cafeeiro. Pesquisa Agropecuária Brasileira, v.26, p.447-453, 1991.

CARNEIRO, J.G.A. Produção e controle de qualidade de mudas florestais. Curitiba: UFPR) FUPEF, 1995. 451 p.

FAVARIN, J.L.; FAVARIN JUNIOR, J.L.; REIS, A.R.; CAMARGO, F.T. Metodologia para estimar a estabilidade do conjunto muda x substrato de cafeeiro. Ciência Rural, v.38, n.1, p.34-38, 2008.

FURTINI NETO, A.E.; VALE, F.R.; RESENDE, A.V.; GUILHERME, L.R.G.; GUEDES, G.A.A. Fertilidade do solo. Lavras: UFLA/ FAEPE, 2001. 252p.

FARIA, C.M. B.; COSTA, N.D.; FARIA, A.F. Ação de calcário e gesso sobre características químicas do solo e na produtividade e qualidade do tomate e melão. Horticultura Brasileira, Brasília, v. 21, n. 4, p. 615-619, 2003.

FERREIRA, D.F. Análises estatísticas por meio do SISVAR para Windows 4.0. In: REUNIÃO ANUAL DA REGIÃO BRASILEIRA DA SOCIEDADE INTERNACIONAL DE BIOMETRIA, 45., 2000, São Carlos. Anais... São Carlos, Universidade Federal de São Carlos, p. 255-258, 2000. 
GUIMARÃES, P.T.G. et al. Cafeeiro. In: RIBEIRO, A.C.; GUIMARÃES, P.T.G.; ALVAREZ, V.H.V. (Eds.). Recomendações para o uso de corretivos e fertilizantes em Minas Gerais: 5a aproximação. Viçosa: CSFSEMG/UFV, 1999. p. 289-302.

GOMES, J.M. Parâmetros morfológicos na avaliação da qualidade de mudas de Eucalyptus grandis, produzidas em diferentes tamanhos de tubete e de dosagens de N-P-K. 2001. 126f. Tese (Doutorado em Ciência Florestal). Universidade Federal de Viçosa, Viçosa.

HSIAO, T.C. Plant responses to water stress. Annual Review of Plant Physiology, v.24, n.1, p. 519-570. 1973.

JONES JUNIOR, J.B.; WOLF, B.; MILLS, H.A. Plant analysis handbook: A practical sampling, preparation, analysis and interpretation guide. Athens, Micro Macro $\mathrm{Pu}$ blishing, 1991. 213p.

MARQUES, H.S. Uso de geotecnologias no estudo das relações entre solos, orientação de vertentes e o comportamento espectral de áreas cafeeiras em Machado, Minas Gerais. 2003. 82p. Dissertação (Mestrado em Solos e Nutrição de Plantas) - Universidade Federal de Lavras.

MATIELLO, J.B.; SANTINATO, R; GARCIA, A.W.R.; FERNANDES, D.R. Cultura do café no Brasil: novo manual de recomendações. Fundação PROCAFÉ. Edição revisada, ampliada e ilustrada. Rio de Janeiro/ Varginha, 2005.
MEXAL, J. L.; LANDS, T. D. Target seedling concepts: height and diameter. In: TARGET SEEDLING SYMPOSIUM, MEETING OF THE WESTERN FOREST NURSERY ASSOCIATIONS, GENERAL TECHNICAL REPORT RM-200, 1990, Roseburg. Proceedings... Fort. Collins: United States Departament of Agriculture, Forest Service, 1990. p. 17-35.

MALAVOLTA, E. Manual de Nutrição Mineral de Plantas. São Paulo: Agronômica Ceres, 2006. 638p.

MARSCHNER, H. Mineral nutrition of higher plants. 2. ed. London: Academic Press, 1995. 889 p.

PARVIAINEN, J.V. Qualidade e avaliação de qualidade de mudas florestais. In: SEMINÁRIO DE SEMENTES E VIVEIROS FLORESTAIS, 1., 1981, Curitiba. Anais... Curitiba: FUPEF, 1981. p. 59-90.

RAGASSI, C.F. Efeito da localização de nutrientes em profundidade para o crescimento radicular. Universidade de São Paulo. Paces... Escola Superior de Agricultura "Luiz de Queiroz", São Paulo, 2007. Disponível em: http://www.paces.com.br/relatorio_arquivo.html>. Acesso em: 23/09/08

SHELP, B.J. Physiology and biochemistry of boron in plants. In: GUPTA, U.C. Boron and its role in crop production. Boca Raton: CRC Press, 1993. p.53-85.

TAIZ, L.; ZEIGER, E. Plant physiology. 3. ed. Sunderland, Massachusetts: Sinauer Associates, Inc., Publishers. 2002. 690 p. 